\title{
From Use to Abuse: When Everyday Consumption Behaviours Morph Into Addictive Consumptive Behaviours
}

\author{
AUTHOR(S): Aditi Grover ${ }^{1}$, Michael A. Kamins ${ }^{2}$, Ingrid M. Martin ${ }^{3}$, Scott Davis ${ }^{4}$, Kelly \\ Haws $^{5}$, Ann M. Mirabito ${ }^{6}$, Sayantani Mukherjee ${ }^{7}$, Dante Pirouz ${ }^{8}$, and Justine Rapp ${ }^{9}$
}

\section{ABSTRACT}

Addiction does not begin with the harmful effects of being dependent on a particular consumption behaviour such as smoking, alcohol, or illegal drugs. Instead it starts with everyday seemingly benign behaviours that, through psychological, biophysical, and/or environmental triggers, can become harmful and morph into an addiction. We develop a framework based on harm and dependence that can help researchers better understand how consumers could become addicted to various types of everyday benign consumption behaviours (e.g., texting, shopping, plastic surgery, and other types of normally acceptable behaviours). Furthermore, the conceptual framework is based on expanding the concept of addiction to include the pre-addiction process with a focus on this continuum of benign to harmful behavioural consumption. This framework describes how consumers progress from a normal state of consumption into a state of addictive abuse and dependence. The framework discusses key issues and future research that can aid public policy researchers, practitioners, and marketers to better understand the entire pre-addiction process.

\section{ARTICLE}

Addiction, although conventionally associated with substance abuse such as drugs, alcohol, and tobacco (American Psychiatric Association Task Force on DSM-IV 2000), is increasingly being observed in various domains of an individual's life. For example, past research has reported that even beneficial behaviours such as exercising, when practiced obsessively, can trigger negative consequences and become abusive, creating a dependence on the behaviour (Terry, Szabo, and Griffiths 2004). Likewise, a recent study conducted by researchers at the University of Maryland's International Center for Media and the Public Agenda (ICMPA), found that people who were asked to stay away from emails, text messages, Facebook, and Twitter updates for 24 hours developed withdrawal symptoms typically seen in smokers attempting to give up smoking (Moeller et al. 2010). Indeed, emerging research suggests that the same neural circuitry in the brain is involved in response to rewards obtained from seemingly benign repetitive behaviours such as

\footnotetext{
${ }^{1}$ Aditi Grover - Plymouth State University, ${ }^{2}$ Michael A. Kamins - Stony Brook University, ${ }^{3}$ Ingrid M. Martin California State University, Long Beach, ${ }^{4}$ Scott Davis - Texas A\&M University, ${ }^{5}$ Kelly Haws - Texas A\&M University, ${ }^{6}$ Ann M. Mirabito - Baylor University, ${ }^{7}$ Sayantani Mukherjee - California State University, Long Beach, ${ }^{8}$ Dante Pirouz - University of Western Ontario, ${ }^{9}$ Justine Rapp - University of Nebraska - Lincoln
} 
exercising to more problematic behaviours such as gambling and substance abuse (Breiter et al. 2001).

Findings such as those above raise an important question: When and how do seemingly benign and even beneficial everyday consumption behaviours transform into an addiction? Previous research on addiction, primarily within the psychiatry, psychology, medical, and public policy literatures, has largely focused on the clinical aspects of addiction as an outcome (e.g., Altman et al. 1996; Goldstein 1992; Kalivas and Volkow 2005). Moreover, the majority of past research characterizes addiction specifically as substance abuse linked to both illicit (e.g., marijuana, cocaine and heroin) and legal (e.g., alcohol, tobacco) pharmacological substances (American Psychiatric Association Task Force on DSM-IV 2000). While the marketing literature has some preliminary research that focuses on compulsive behaviours (e.g., Hirschman and Holbrook 1982; Rook 1987), little has been done to explicate how an individual can move towards addictive abuse and dependence (Frances 2010), which we call the pre-addiction process. Thus, most research has examined the post-addiction process rather than the process by which individuals become addicted to a consumption behaviour or product.

\section{The Proposed Framework}

To address this gap, our framework as illustrated in the Figure highlights the process leading to addiction, inclusive of the behavioural characteristics that are manifested before a consumer can be labelled an addict. We seek to highlight the pre-addiction process across numerous domains of a consumer's life without limiting the behaviour to conventional substance abuse. In doing so, we present a conceptual framework examining harm and dependence that emphasizes the inflection points where benign consumption behaviours morph into addictive consumption behaviours.

Figure: Pre-Addiction - Addiction Process Framework

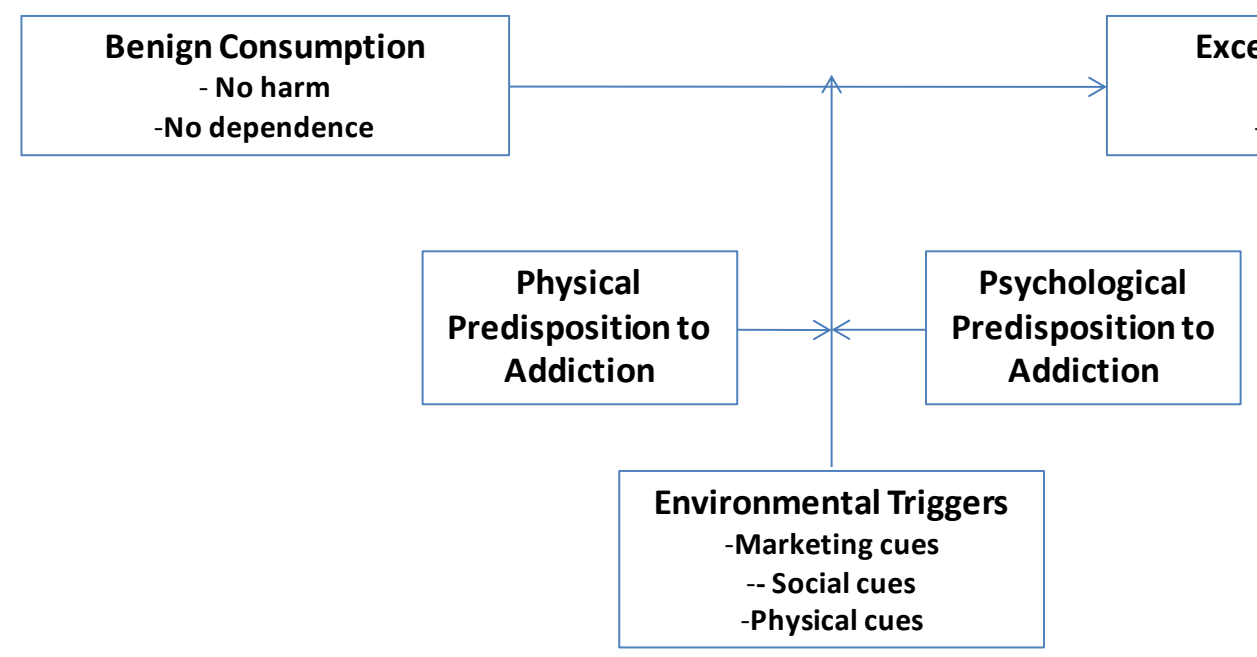

In order to conceptualize the increased engagement in a broad array of consumption behaviours, we propose a pre-addiction process that examines these behaviours from the perspective of harm and dependence. The pre-addiction process is based on an individual engaging in a behaviour that is relatively benign and without harmful consequences but progressively moving toward being harmful as the individual becomes more and more dependent on the consumption behaviour or product (Campbell 2003; Koob and LeMoal 2001). Consider Sydney, who enjoys online gambling as a way to divert her attention from 
other stresses in her life. As her consumption of online gambling increases, she reaches a tipping point where she no longer can stay away from the Internet sites for gambling, and negative consequences begin to emerge (e.g., spending more than she or her family can afford) (Hoch and Lowenstein 1991).

The key dimensions of the pre-addiction process include 1) the time spent on the behaviour, 2) the degree of self-control exerted by the individual, where self-control is characterized by a non-volitional focus on the process of delaying gratification of certain needs or impulses, 3) the enjoyment of the behaviour, and 4) the degree of negative consequences manifested in terms of psychological, economic, physical, and/or social outcomes (Charlton 2002; Hoch and Lowenstein 1991). Essentially, a progression towards dependence relates to an increase in the time spent on the behaviour, the individual's loss of self-control and enjoyment derived from doing it while harm can relate to the individual, his/her family, and society.

A decision to engage in a particular behaviour may start with low involvement or even apathy. Typically, the time that individuals spend on the behaviour is low, the degree of selfcontrol exerted is high, enjoyment is high, and degree of harmful consequences is low or even non-existent. For example, the decision to try your luck at online gambling can be done on the basis of curiosity with little if any concern for some harmful outcomes. Rewards for the behaviour may motivate higher involvement and increased time spent engaging in the behaviour. The individual may begin to develop a tolerance for the behaviour and require higher doses to achieve enjoyment (Charlton 2002). However, the behaviour is still relatively benign and largely under the individual's control, while the risk of harmful consequences is rising. As an individual moves up the pre-addiction continuum, the time spent increases, and usage is now driven by a loop designed to extract ever-decreasing enjoyment resulting in the psychological or physical need to engage in the behaviour. This stage may be characterized by enhanced engagement, where the activity begins to become something wanted rather than liked (Robinson and Berridge 1993). Self-control decreases, while the negative consequences from the behaviour increase (Rook and Hoch 1985). In sum, these nonimpulsive, benign behaviours transition towards compulsive, harmful behaviours as the individual arrives at the inflection point on the path to addiction (Martin, Kamins, Grover, et al. 2011).

Berridge and Robinson (1995) found that the process of addiction leads to disassociating the process of wanting from the process of liking. Thus, as the wanting of a substance increases, the liking of a given dose fades (Breiter et al. 2001; Robinson and Berridge 1993). We characterize this switch from liking to wanting as the inflection point in the pre-addiction process. The 'tipping point' between high involvement and addictive behaviour signals the shift from seemingly normal, enjoyable, or mundane behaviours to the realm of dysfunction, driven by physical and/or psychological wanting and rapid loss of self-control. Next we discuss how the proposed pre-addiction framework offers several interesting future research initiatives for transformative consumer researchers.

\section{Key Issues and Future Research Directions}

Our conceptualization of the pre-addiction process includes behavioural addictions such as technology uses (e.g., texting), exercising, plastic surgery, eating, shopping, and other types of consumption behaviours, as well as the traditional legal and illegal substance uses. This broader conceptualization calls for an understanding of the role of marketing cues in moving consumers along the pre-addiction continuum. 


\section{Marketing Cues in the Pre-addiction Process}

One of the key implications of our proposed framework is an increased emphasis on identifying the role of marketing cues in the pre-addiction process, as illustrated in the Figure. Consumer research has a long tradition of examining how consumers react differentially to subtle and sometimes not so subtle, cues that may influence behaviour (e.g., Berger and Fitzsimons 2008). Indeed, marketing cues may facilitate or inhibit the development and engagement of these types of potentially addictive consumption behaviour.

Commercial marketing communications often emphasize the benefits of consumption and minimize the risks. Orford et al. (2002) observed that the perceived benefits of drinking outweighed the drawbacks for heavy drinkers. This finding suggests an opportunity to better understand how to creatively communicate the benefits of the potential addictive behaviour while more heavily weighting the harm. The presentation format is not always apparent. For example, showing smokers images of diseased lungs and other physical failings has little impact on their consumption of the product despite showing the ultimate harm - death. In some cases, even among those who recently began to smoke, such communications have been observed to result in a boomerang effect, that is, moving smokers up the pre-addiction continuum (Wolburg 2006). For example, college-age smokers faced with images of disease and death deny that it could happen to them or reason that they would stop before they would fall victim to the behaviour (Martin and Kamins 2010). However, ads which show the death of social relationships (e.g., the death of family members as a result of the individual engaging in smoking) seem to provide some promise in getting smokers to reduce smoking or even quit the habit, specifically for those who value familial relationships (Martin, Kamins, Grover, and Connell 2011).

Marketers may be able to reinforce self-control and prevent addiction by making trade-offs salient. Research in consumption has shown that consumers will continue eating beyond a point of satiation, as demonstrated by Wansink (2005) in the bottomless soup bowl experiment. Sales tactics pushing bigger portion sizes or "all you can eat buffets" may unintentionally promote food addictions by linking consumers' desire for value with impaired self-regulatory capabilities. Marketing communications sometimes downplay the gravity of potential overconsumption, leading to harmful behaviours. Overeating is humorous at the Las Vegas-based Heart Attack Grill, which features Quadruple By-Pass Burgers and lard-cooked fries served by waitresses dressed up as nurses. What is needed is a clearer emphasis on recommended serving sizes, and not the notion that bigger is always better ("Big Gulp," "Whopper," "Super Size It"). Consumer researchers have an opportunity to uncover compelling communication strategies that do not exploit consumer weaknesses.

\section{Co-morbidity and Addiction Transfer in the Pre-addiction Process}

Our conceptualization of the pre-addiction process on dimensions related to harm and dependence may deepen our understanding of mechanisms such as co-morbidity and addiction transfer. Co-morbidity refers to individuals engaged in more than one type of problematic consumption behaviours (e.g., excessive eating as well as excessive shopping, heavy smoking, and binge drinking). In contrast, addiction transfer refers to the introduction of one potentially addictive behaviour while successfully disengaging from another addictive behaviour. For example, consumers may disengage from excessive eating but may replace it with another behaviour such as excessive shopping (Hagedorn et al, 2007). However, most research in this area focuses on the post-addiction stage. Our framework suggests that it is important to examine co-morbidities in the pre-addiction stage. In particular, it implies that consumers may simultaneously move along the pre-addiction continuum in multiple consumption domains early on. Thus, it is important not only to examine specific consumption behaviours but also investigate a portfolio of everyday consumption behaviours that can morph into addictive behaviours. For example, consumer researchers have exposed 
co-morbidities between compulsive buying and binge eating (Faber et al. 1995), pathological gambling and alcohol consumption (Blinn-Pike and Worthy 2008), as well as smoking and alcohol dependence (Dani and Harris 2005).

Similarly, one can examine pre-addiction transfer, whereby consumers may engage in benign consumption in one domain but may progress towards addiction in another consumption domain. In addition, broadening our focus from post-addiction to pre-addiction processes allows us to shift our emphasis from physiological responses associated with comorbidity and addiction transfer to the behavioural underpinnings through which addiction can be manifested in multiple seemingly benign consumption domains. Further, by examining the pre-addiction process, researchers can identify the "addiction potential" of diverse everyday consumption domains. Moreover, they can be forewarned that by arresting one addiction, the recovering addict is susceptible to transferring such tendencies to current behaviour that at a pre-addiction stage is not currently problematic (Hatcher 1989).

\section{Conclusion}

There is much to be learned by examining addictive consumption behaviours beyond the addiction literature (focus on substances with chemically-addictive ingredients) to include behaviours such as excessive shopping and eating. Our research makes three key contributions to the addiction literature. First, by conceptualizing addiction on dimensions of degree of time spent on the behaviour, self-control exerted by the individual, enjoyment of the behaviour, and negative consequences, researchers can focus on the process by which seemingly benign behaviours morph into harmful, addictive behaviours. Second, our framework calls for a focus on the pre-addiction process that leads to addiction, since behaviour change is more difficult to accomplish once addiction takes place. Finally, we present some possible means by which marketing cues can either inhibit or facilitate movement along the pre-addiction continuum. Much research is needed to develop an indepth understanding of this process.

\section{References}

Adriani, Walter, Sabine Spijker, Veronique Derouche-Gamonet, Giovanni Laviola, Michel Le Moal, August Smit, and Pierre Vincenzo Piazza (2003), "Evidence for Enhanced Neurobehavioral Vulnerability to Nicotine during Periadolesence in Rats," Journal of NeuroScience, 23 (June), 4712-4716.

Altman Janet, Barry J. Everitt, Steven Glautier, Athina Markou, David Nutt, R. Oretti, Gavin D. Phillips, and Trevor W. Robbins (1996), "The Biological, Social and Clinical Bases of Drug Addiction: Commentary and Debate," Psychopharmacology, 125 (4), 285-34.

American Psychiatric Association Task Force on DSM-IV (2000), Diagnostic and Statistical Manual of Mental Disorders: DSM-IV-TR, Arlington, VA: American Psychiatric Publishing, Inc.

Berger, Jonah and Gráinne M. Fitzsimons (2008), "Dogs on the Street, Pumas on Your Feet: How Cues in the Environment Influence Product Evaluation and Choice," Journal of Marketing Research, 45 (1), 1-14.

Bernheim, B. Douglas and Antonio Rangel (2004), "Addiction and Cue-triggered Decision Processes," American Economic Review, 94 (5), 1558-1590.

Berridge, Kent C., and Terry E. Robinson (1995), "The Mind of an Addicted Brain: neural Sensitization of Wanting Versus Liking," Current Directions in Psychological Science, 4 (June), 71-76.

Blinn-Pike, Lynn and Sherri L. Worthy (2008), "Undergraduate Women Who Have Gambled in Casinos: Are They at Risk?," Family and Consumer Sciences Research Journal, 37 (1), 71-83. 
Blume, Sheila B. and Hermano Tavares (2005), "Pathologic Gambling," in J. H. Lowinson, P. Ruiz, R. B. Millman, S. P. Steinberg and J. G. Langrod, eds. Substance Abuse: A Comprehensive Textbook. Philadelphia, PA: Lippincott Williams \& Wilkins, pp. 488498.

Breiter, Hans C., Itzhak Aharon, Daniel Kahneman, Anders Dale and Peter Shizgal (2001), "Functional Imaging of Neural Responses to Expectancy and Experience of Monetary Gains and Losses," Neuron, 30 (2), 619-639.

Burks, Ron (2005), "Addiction and Cults: Synthesizing a Model for Treating Ex-Members," in J. H. Lowinson, P. Ruiz, R. B. Millman, S. P. Steinberg and J. G. Langrod, eds. Substance Abuse: A Comprehensive Textbook, Philadelphia, PA: Lippincott Williams \& Wilkins, pp.498-504.

Campbell, William G. (2003), "Addiction: A Disease of Volition Caused by a Cognitive Impairment," Candadian Journal of Psychiatry, 48 (November), 669-674.

Charlton, J.P. (2002), "A Factor-Analytic Engagement of Computer 'Addiction' and Engagement," British Journal of Psychology, 93(August), 329-44.

Cheema, Amar and Dilip Soman (2008), "The Effect of Partitions on Controlling Consumption" Journal of Marketing Research, 45 (December), 665-675.

Chumbley, Justin and Mark Griffiths (2006), "Affect and the Computer Game Player: The Effect of Gender, Personality, and Game Reinforcement Structure on Affective Responses to Computer Game-Play," CyberPsychology and Behavior, 9 (3), 308316.

Curry, Susan J. and Colleen M. McBride (1994), "Relapse Prevention for Smoking Cessation: Review and Evaluation of Concepts and Interventions," Annual Review of Public Health, 15, 345-366.

Dani, John A., and R. Adron Harris (2005), "Nicotine Addiction and Co-Morbidity with Alcohol Abuse and Mental Illness," Nature Neuroscience, 8(November), 1465-70.

Drewnowski, Adam (2010). "The Cost of US Foods as Related to Their Nutritive Value," American Journal of Clinical Nutrition, 92 (5), 1181-1118.

Faber, Ronald J., Gary A. Christenson, Martina De Zwaan, and James Mitchell (1995), "Two Forms of Compulsive Consumption: Comorbidity of Compulsive Buying and Binge Eating," Journal of Consumer Research, 22 (3), 296-304.

Frances, Allen (2010), "Opening Pandora's Box: The 19 Worst Suggestions for DSM5," Psychiatric Times, February 11.

Gearhardt, Ashley N., William R. Corbin, and Kelly D. Brownell (2009), "Preliminary Validation of the Yale Food Addiction Scale," Appetite 52, 430-436.

Gold, Mark S. and Jodi Star (2005), "Eating Disorders", in J. H. Lowinson, P. Ruiz, R. B. Millman, S. P. Steinberg and J. G. Langrod, eds. Substance Abuse: $A$ Comprehensive Textbook, Philadelphia, PA: Lippincott Williams \& Wilkins, pp. 469488.

Goldstein, Avram. "Heroin maintenance: A medical view. A conversation between a physician and a politician," Journal of Drug Issues, 9, 341-347, 1979.

Goodman, Aviel (1990), "Addiction: Definition and Implications," British Journal of Addiction, 85 (11), 1403-1408.

Goodman, Aviel (2005), "Sexual Addiction: Nosology, Diagnosis, Etiology, and Treatment," in J. H. Lowinson, P. Ruiz, R. B. Millman, S. P. Steinberg and J. G. Langrod, eds. Substance Abuse: A Comprehensive Textbook, Philadelphia, PA: Lippincott Williams \& Wilkins, pp. 504-539.

Grant, Jon E., Brian L. Odiaug, and Suck Won Kim (2010), " Kleptomania: Clinical Characteristics and Relationship to Substance Use Disorders," American Journal of Drug and Alcohol Abuse, 36 (5), 291-29.

Greenberg, John, Thomas Pyszczynski, and Stephen Solomon (1996), "Evidence of a Terror Management Function of Cultural Icons: The Effects of Mortality Salience on the Inappropriate Use of Cherished Cultural Symbols," Personality and Social Psychology Bulletin, 21 (11), 1221-28. 
Hagedorn Judith C, Betsy Encarnacion, Gabriel A. Brat, and John M. Morton (2007),"Does Gastric Bypass Alter Alcohol Metabolism?," Surgery for Obesity and Related Diseases, 3 (5), 543-548.

Halperin, David A. and Jane Glick (2005), "Collecting, Accumulation, and Hoarding: Acquisitions and Their Discontents," in J. H. Lowinson, P. Ruiz, R. B. Millman, S. P. Steinberg and J. G. Langrod eds. Substance Abuse: A Comprehensive Textbook, Philadelphia, PA: Lippincott Williams \& Wilkins, pp.548-558.

Hatcher, Anna S. (1989), "From one Addiction to Another, Life After Alcohol and Drug Abuse," Nurse Practitioner, 14 (November), 33-41.

Hoch, Stephen J., and George F. Loewenstein. 1991. "Time-inconsistent Preferences and Consumer Self-Control," Journal of Consumer Research, 17 (March): 492-507.

Holbrook, Morris C., and Elizabeth C. Hirschmann (1982), "The Experiential Aspects of Consumption: Consumer Fantasies, Feelings, and Fun," Journal of Consumer Research, 9, (2), 132-40.

Hough, Andrew (2011), "Student Addiction to Technology Similar to Drug Cravings, Study Finds," The Telegraph, www.telegraph.co.uk/technology/news/8436831/Studentaddiction-to-technology-similar-to-drug-cravings-study-finds.html.

Kalivas, Peter and N. D. Volkow (2005), "The Neural Basis of Addiction: A Pathology of Motivation and Choice," American Journal of Psychiatry, 162, 1403-1413.

Koob, George F. and Michel LeMoal (2001), "Drug Addiction, Dysregulation of Reward and Allostasis," Neuropsychopharmacology, 24 (2), 97-129.

Lynch, John G., Jr., Richard Netemeyer, Stephen A. Spiller, and Alessandra Zammit (2010), "A Generalizable Scale of Propensity to Plan: The Long and the Short of Planning for Time and Money," Journal of Consumer Research, 37 (June), 108-128.

Madden, Pamela.A.F., Andrew.C. Heath, G.A. Starmer, J.B. Whitfield and Nicholas G. Martin (2006), "Alcohol Sensitivity and Smoking History in Men and Women," AlcoholismClinical and Experimental Research, 19 (5), 111-1120.

Martin, Ingrid M., Michael A. Kamins, Aditi Grover and Paul Connell (2011), "Self Affirmation and Terror Management Theory: The importance of familial relationships in consumption behaviors?" Unpublished Working Paper, California State University at Long Beach.

Martin, Ingrid M. and Michael A. Kamins (2010), "Relationships Can Disappear in a Puff of Smoke: A Test of Terror Management Theory and Risk Perceptions on Smoking Behavior" Journal of Consumer Behaviour, forthcoming.

Martin, Ingrid M., Michael A. Kamins, Aditi Grover, Scott Davis, Kelly Haws, Ann M. Mirabito, S. Mukherjee, Dante Piroux, and Justine Rapp, (2011), "On the Road to Addiction: Can Marketing Cues Block or Facilitate the Path," (working paper), California State University at Long Beach.

Mick, David G. (1996). "Are Studies of Dark Side Variables Confounded by Socially Desirable Responding? The Case of Materialism," Journal of Consumer Research, 23 (September), 106-119.

Moeller, Susan, Eunryung Chong, Sergei Golitsinski, Jing Guo, Raymond McCaffrey, Raymond, Andrew Nynka, Jessica Roberts (2010). "24 Hours: UnPlugged", Retrieved from http://withoutmedia.wordpress.com/.

Nutt, D., King, L. A., Saulsbury, W., \& Blakemore, C. (2007). "Development of a Rational Scale to Assess the Harm of Drugs of Potential Misuse," The Lancet, 369 (9566), 1047-1053.

Orford, Jim, Sue Dalton, Elizabeth Hartney, Maria Ferrins Brown, Cicily Kerr and jennifer Maslin (2002), "How is Excessive Drinking Maintained? Untreated Heavy Drinkers Experience of the Personal Benefits and Drawbacks of Their Drinking," Addiction Research and Theory, August (10), 347-72.

Pechmann, Cornelia, Guangzhi Zhao, Marvin E. Goldberg, and Ellen Thomas Reibling (2003), " What to Convey in Antismoking Advertisements for Adolescents: The Use of Protection Motivation Theory to Identify Effective Message Themes," Journal of Marketing, 67 (2), 1-18. 
Prochaska, James O. and John C. Norcross (2001) "Stages of Change," Psychotherapy: Theory, Research, Practice, Training, 38 (4): 443-448.

Robinson, Terry E., and Kent C. Berridge (1993), "The Neural Basis of Drug Craving: An Incentive Sensitization Theory of Addiction," Brain Research Review, 18:247-291.

Rook, Dennis W. (1987). "The Buying Impulse", Journal of Consumer Research, 14 (September), 189-99.

Rook, Dennis W., and Stephen J. Hoch (1985), "Consuming Impulses," in Advances in Consumer Research, Vol. 12, eds. Morris B. Holbrook and Elizabeth C. Hirschmann. Provo Utah. Association for Consumer Research, 23-27.

Taintor, Zebulon (2005), "Internet/Computer Addiction," in J. H. Lowinson, P. Ruiz, R. B. Millman, S. P. Steinberg and J. G. Langrod, eds. Substance Abuse: $A$ Comprehensive Textbook, Philadelphia, PA: Lippincott Williams \& Wilkins, pp. 540548.

Terry, Annabel, Attila Szabo, and Mark Griffiths (2004), "The Exercise Addiction Inventory: A New Brief Screening Tool." Addiction Research \& Theory, 12 (5): 489-499.

Ullrich, John, U., Christian. Meyer, Hans-Jurgen Rumph and Ullfert Hapke (2003), "Probabilities of Alcohol High-Risk Drinking Abuse or Dependence Estimated on Grounds of Tobacco Smoking and Nicotine Dependence," Addiction, 98 (6), 805-14.

Wansink, Brian (2006), Mindless Eating: Why We Eat More Than We Think, Bantam Books.

Wolberg, Joyce M. (2006), "College Students' responses to Anti-Smoking Messages: Denial, Defiance, and Other Boomerang Effects," Journal of Consumer Affairs, 40(2), 294323.

Wright, Mary Ruth (1986), "Surgical Addiction: A Complication of Modern Surgery?" Archives of Otolaryngology- Head and Neck Surgery, 112(8), 870-872. 